\title{
Hyperferritinemia Has Multifactorial Etiology in Naive Patients with Chronic Hepatitis C
}

\author{
Ibrahim Ahmad Hussein El Bacha*, Maria Cristina Elias, Ivonete Sandra de Souza e Silva, Ayk Helena Barbosa \\ Martins and Edison Roberto Parise
}

Departamento de Medicina, Disciplina de Gastroenterologia, Universidade Federal de São Paulo Ibrahim, Brazil

Submission: June 15, 2020; Published: July 10, 2020

*Corresponding author: Ibrahim Ahmad Hussein El Bacha, Departamento de Medicina, Disciplina de Gastroenterologia, Universidade Federal de São PauloRua Loefgren, 1726- São Paulo - SP CEP 04040-002, Brazil

\begin{abstract}
Background \& Aim: Traditionally, elevated serum ferritin is related to the presence of iron accumulation in the body, especially in the liver. However, in chronic hepatitis C several other factors have been alternatively associated with hyperferritinemia, such as liver enzymes, metabolic factors, hepatic steatosis and liver fibrosis. This study aimed to evaluate the exact contribution of these variables to ferritin serum levels in chronic hepatitis.

Methods: Naïve patients with chronic hepatitis C were selected retrospectively and their ferritin serum levels were correlated with demographic data (age and gender), biochemical (AST, ALT, GGT, ALP and glucose by automated methods; insulin by immunofluorimetry), virological (viral load and genotyping) and histological variables(degree of steatosis, inflammation and staging). Statistical analysis was performed by ANOVA complemented by Dunn's test and logistic regression analysis.

Results: In two hundred and eighty-two patients with mean age of 50 years and a predominance of male patients (56\%) and genotype 1 (65\%),the mean serum ferritin levels were $561 \mathrm{ng} / \mathrm{mL}$ for males and $270 \mathrm{ng} / \mathrm{mL}$ for females with a significant difference in ferritin levels between genders, irrespective of age. The mean HOMA-IR was 3.23 Histological examination showed that $23.4 \%$ of the patients had liver cirrhosis, $64.2 \%$ fatty liver, and $20 \%$ hepatic siderosis. The factors independently associated with hyperferritinemia in multivariate logistic regression analysis were ALT ( $p=0.037)$, GGT ( $<<0.001)$, hepatic siderosis $(p=0.002)$, steatosis $(p=0.027)$, and HOMA-IR $(p=0.014)$.

Conclusion: In treatment- naïve patients with chronic hepatitis $\mathrm{C}$, hyperferritinemia has a multifactorial etiology.

Keywords: Serum ferritin; Siderosis; HOMA-IR; Steatosis; Hepatic fibrosis; Chronic hepatitis C

Abbreviations: HCV: hepatitis C Vírus; HBV: Hepatitis B Vírus; HIV: Human Immunodeficiency Vírus; PCR: Polymerase Chain Reaction; AST: Alanine Aminotransferase; ALT: Aspartate Aminotransferase; GGT: Gamma- Glutamyl Transferase; HOMA-IR: Homeostasis Model Assessment of
\end{abstract} Insulin Resistance; PPA: Periportal Activity

\section{Introduction}

Hyperferritinemia is a frequent finding in chronic hepatitis $\mathrm{C}$ and affects about 20 to $30 \%$ of patients; however, only a small percentage of these patients show evidence of iron accumulation in tissue [1,2]. The increase in ferritin associated with iron overload in patients with chronic hepatitis $\mathrm{C}$ has been attributed to alterations in the secretion of hepcidin, a hormone secreted by the liver that regulates intestinal iron absorption $[3,4]$ as well as to other concomitant diseases such as hereditary hemochromatosis, hematological diseases, multiple blood transfusions, porphyria cutanea tarda, chronic alcoholism, and hemodialysis. In the absence of siderosis, hyperferritinemia in hepatitis $\mathrm{C}$ has also been associated with inflammatory activity such as acute- phase proteins, tumor growth and, recently, abnormal glucose metabolism especially in the presence of type 2 diabetes mellitus [5-7]. In addition, increased levels of this transport protein are related to the presence of hepatic steatosis and oxidative stress, and the response to antiviral therapy with interferon $[8,9]$.

Considering the large number of factors that have been associated with hyperferritinemia in patients with chronic hepatitis $\mathrm{C}$, the objective of the present study was to evaluate the correlation of serum ferritin levels with demographic, histological and biochemical (liver enzymes and insulin resistance syndrome) parameters in treatment-naïve patients with chronic hepatitis $\mathrm{C}$. 


\section{Materials and Methods}

This was a retrospective study that evaluated the records of patients chronically infected with hepatitis $\mathrm{C}$ virus (HCV), followed up at the Liver Disease Outpatient Clinic of the Department of Gastroenterology, Unifesp. Patients who met the following criteria were included: infection with HCV (confirmed by the detection of HCV- RNA in serum), liver biopsy with a diagnosis of chronic hepatitis, and determination of blood ferritinlevels.

Exclusion criteria were coinfection with HBV and/or HIV, chronic alcohol consumption ( $>20 \mathrm{~g}$ /day), presence of debilitating diseases, use of immunosuppressors, previous antiviral therapy, a history of multiple blood transfusions, iron replacement therapy, known hematological disease, known chronic systemic diseases, current or past gastrointestinal bleeding, hepatocellular carcinoma, and other known neoplasms.

HCV-RNA was investigated and quantified in serum by the polymerase chain reaction (PCR) using the Cobas Amplicor Test (Roche Diagnostic System, USA), with a detection limit of 50 IU/ mL. Genotyping of HCV was performed by sequencing of the 5'UTR region. Serum levels of alanine aminotransferase (AST), aspartate aminotransferase (ALT), gamma-glutamyl transferase (GGT), alkaline phosphatase, and glucose were measured by an automated kinetic method. Serum ferritin was determined by chemiluminescence, with the maximum normal limit of the central laboratory being $400 \mathrm{ng} / \mathrm{mL}$ for men and $150 \mathrm{ng} / \mathrm{mL}$ for women, regardless of age. These values were used as cutoffs for the categorization of ferritin. Altered blood glucose was defined as levels $\geq 100 \mathrm{mg} / \mathrm{mL}$. Serum insulin was determined by an immunofluorimetric assay (Perkin Elmer BR-CS). The homeostasis model assessment of insulin resistance (HOMAIR) index was calculated using the formula HOMA-IR = [glucose (nmol/L) * insulin (mU/mL) / 22.5] [10] and an index > 2.5 was considered to be altered [11].

Biopsy specimens were routinely submitted to hematoxylineosin staining, silver staining of reticulin fibers (Gomori method), and staining with Masson's trichrome. The classification of necroinflammatory activity and staging of chronic hepatitis were performed using the criteria of the Brazilian Societies of Pathology and Hepatology [12]. The histological variables were categorized as the presence or absence of steatosis and liver siderosis $(0 \times 1$, 2 and 3). Inflammatory activity was classified according to the periportal activity (PPA) as absent or mild versus moderate or intense (PPA 0 and 1 x PPA 2, 3 and 4) and structural alterations according to the presence or absence of advanced fibrosis (F0-F2 $x$ F3,F4). For the semi-quantitative analysis of iron, the liver tissue fragments were stained with Prussian blue (Perls method). This analysis included the grading of liver siderosis using a system ranging from 0 to 4 , where grade 0 (absence of iron deposits), grade 1 (iron granules visible at 400x magnification), grade 2 (discrete iron granules visible at 100x magnification), grade 3 (iron granules visible at $25 \mathrm{x}$ magnification), and grade 4 (mass of iron granules visible at 10x magnification or with the naked eye) (13). Using this system, the patients were classified as having absent or mild liver siderosis (grades 0 and 1) or intense siderosis (grades 2 to 4).

Statistical analysis was performed using the SPSS 10 program. Mean values of the continuous variables were compared by analysis of variance (ANOVA), complemented by Dunn's test. The $c^{2}$ test was used to compare frequencies and Spearman's coefficient to evaluate the correlation between the variables studied. Binary logistic regression analysis was performed after categorization of the variables. The liver enzyme cut-offs were determined from receiver operating characteristic (ROC) curves.

\section{Results}

A total of 282 patients with chronic hepatitis C were included in the study. The demographic, biochemical, virological and histological data of the patients are shown in Tables $1 \& 2$. The patients with chronic hepatitis $\mathrm{C}$ were divided into four groups according to gender and age (Table 3). Significant differences in ferritin levels were observed between men and women, regardless of age. However, there was no significant difference in ferritin between patients $<50$ and $\geq 50$ years in the same gender.

Table 1: Demographic, biochemical and virological characteristics of the 282 patients with chronic hepatitis C.

\begin{tabular}{|c|c|}
\hline Parameter & $N=282$ \\
\hline Gender (F/M) & $124(44 \%) / 158(56 \%)$ \\
\hline Age (years) & $50.1 \pm 12.8$ \\
\hline BMI $\left(\mathrm{kg} / \mathrm{m}^{2}\right)$ & $25.4 \pm 5.3$ \\
\hline AST (x ULN) & $1.86 \pm 1.85$ \\
\hline ALT (x ULN) & $2.41 \pm 2.44$ \\
\hline GGT $(x$ ULN) & $1.69 \pm 1.76$ \\
\hline Alkaline phosphatase (x ULN) & $0.89 \pm 0.59$ \\
\hline Platelets (count $/ \mathrm{mm}^{3}$ ) & $185.3 \pm 68.9$ \\
\hline Glucose (mg/dL) & $98.8 \pm 26.2$ \\
\hline Insulin (mU/L) & $13.2 \pm 10.3$ \\
\hline HOMA-IR & $3.23 \pm 2.78$ \\
\hline \multicolumn{2}{|l|}{ Ferritin (ug/L) } \\
\hline Male & $561 \pm 598$ \\
\hline Female & $270 \pm 335$ \\
\hline \multicolumn{2}{|l|}{ Viral load (IU/mL) } \\
\hline$<800,000$ & $102(39 \%)$ \\
\hline$>800,000$ & $158(61 \%)$ \\
\hline Genotype 1 & $183(65 \%)$ \\
\hline Non-1 & $99(35 \%)$ \\
\hline
\end{tabular}

Numerical values are expressed as mean \pm Standard Deviation. $\mathrm{N}$ Number; M: Male; F: Female; BMI: Body Mass Index; HOMA-IR: Homeostasis Model Assessment of Insulin Resistance, Adopting the formula: Fasting Insulin $(\mathrm{mU} / \mathrm{mL})$ x Fasting Glucose $(\mathrm{nmol} / \mathrm{L}) / 22.5$; AST: Aspartate Aminotransferase; ALT: Alanine Aminotransferase; GGT: Gamma-Glutamyl Transferase; ULN: Upper Limit of Normal. 


\section{Advanced Research in Gastroenterology \& Hepatology}

Table 2: Histological characteristics of the found in the 282 patients with chronic hepatitis $\mathrm{C}$ according to the criteria of the Brazilian Societies of Pathology and Hepatology12.

\begin{tabular}{|c|c|c|}
\hline Parameter & & $N=282$ \\
\hline \multicolumn{3}{|l|}{ Stage } \\
\hline & 0 & 35 (12.4\%) \\
\hline & 1 & $60(21.3 \%)$ \\
\hline & 2 & $65(23.0 \%)$ \\
\hline & 3 & 56 (19.9\%) \\
\hline & 4 & $66(23.4 \%)$ \\
\hline \multicolumn{3}{|l|}{ PPA } \\
\hline & 0 & $24(08.5 \%)$ \\
\hline & 1 & $54(19.1 \%)$ \\
\hline & 2 & 95 (33.7\%) \\
\hline & 3 & $98(34.8 \%)$ \\
\hline & 4 & $11(03.9 \%)$ \\
\hline \multicolumn{3}{|l|}{ Siderosis } \\
\hline & 0 & 224 (79.4\%) \\
\hline & 1 & 35 (12.4\%) \\
\hline & 2 & $21(7.44 \%)$ \\
\hline & 3 & $2(0.71 \%)$ \\
\hline & 4 & $0(0.0 \%)$ \\
\hline \multicolumn{3}{|l|}{ Steatosis } \\
\hline & 0 & $101(35.8 \%)$ \\
\hline
\end{tabular}

\begin{tabular}{|c|c|c|}
\hline & 1 & $125(44.3 \%)$ \\
\hline & 2 & $44(15.6 \%)$ \\
\hline & 3 & $12(4.3 \%)$ \\
\hline
\end{tabular}

Data are reported as absolute and relative frequency. The criteria of the Brazilian Societies of Pathology and Hepatology (Gayotto et al., 2000) were used for histological classification. PPA: Periportal Activity.

Table 3: Ferritin levels in patients with chronic hepatitis $C(n=282)$ according to gender and age ( $<50$ or $\geq 50$ years).

\begin{tabular}{|c|c|c|}
\hline Group & N & $\begin{array}{c}\text { Serum Ferritin(ug/L) (Mean } \pm \\
\text { standard error) }\end{array}$ \\
\hline Female $<50$ years & 49 & $273 \pm 55^{*}$ \\
\hline Female $\geq 50$ years & 75 & $267 \pm 34^{*}$ \\
\hline Male $<50$ years & 83 & $535 \pm 62$ \\
\hline Male $\geq 50$ years & 75 & $590 \pm 73$ \\
\hline
\end{tabular}

ANOVA complemented by Dunn's test. $\left(^{*}\right) p<0.05$ for comparison of females and males independent of age.

The differences observed justify the use of different cut-off values for gender, but not for the age groups considered, permitting logistic regression analysis to determine the factors associated with serum ferritin levels. The results of uni- and multivariate binary logistic regression analysis are shown in Table 4 . The following variables were significantly associated with ferritinemia in univariate analysis (Table 4): gender, platelet count, AST, ALT, GGT, HOMA-IR, body mass index, histological stage, periportal activity, steatosis, and liver siderosis. However, only ALT, GGT, HOMA-IR, steatosis and siderosis were independently associated with serum ferritin levels.

Table 4: Binary logistic regression analysis of factors associated with hyperferritinemia in the 282 patients with chronic hepatitis $C$ studied.

\begin{tabular}{|c|c|c|c|c|c|}
\hline \multirow[b]{2}{*}{ Variable } & \multicolumn{2}{|c|}{ Univariate } & \multicolumn{3}{|c|}{ Multivariate } \\
\hline & OR & $\mathbf{p}$ & OR & $95 \% \mathrm{CI}$ & $\mathbf{p}$ \\
\hline Age $(<$ or $\geq 50$ years $)$ & 0.329 & 0.566 & & & \\
\hline Gender (M/F) & 12.083 & 0.001 & & & \\
\hline BMI $(<$ or $\geq 25 \mathrm{~kg} / \mathrm{m} 2)$ & 11.072 & 0.001 & & & \\
\hline Platelets ( $\geq$ or $<150,000 / \mathrm{mm} 3$ ) & 7.664 & 0.006 & & & \\
\hline AST (1.35 x ULN) & 17.299 & $<0.001$ & & & \\
\hline $\operatorname{ALT}(1.65 \times$ ULN) & 19.92 & $<0.001$ & 2.213 & $1.048-4.673$ & $0.037^{*}$ \\
\hline GGT $(1.40 \times$ ULN) & 32.568 & $<0.001$ & 2.987 & $1.630-5.472$ & $<0.001^{*}$ \\
\hline Alkaline phosphatase (1.00 x ULN) & 1.966 & 0.161 & & & \\
\hline HOMA-IR $(<$ or $\geq 2.5)$ & 36.741 & $<0.001$ & 2.176 & $1.173-4.038$ & $0.014^{*}$ \\
\hline Stage $(0,1,2$ × 3,4$)$ & 11.176 & 0.001 & & & \\
\hline PPA $(0,1 \times 2,3,4)$ & 10.545 & 0.001 & & & \\
\hline Steatosis $(0 \times 1,2,3)$ & 14.153 & $<0.001$ & 1.918 & $1.078-3.413$ & $0.027^{*}$ \\
\hline Siderosis $(0 \times 1,2,3)$ & 20.142 & $<0.001$ & 3.749 & $1.654-8.499$ & $0.002^{*}$ \\
\hline Viral load (> or < 8 x 106 IU/mL) & 1.579 & 0.209 & & & \\
\hline Genotype (1/non-1) & 0.067 & 0.796 & & & \\
\hline
\end{tabular}

BMI: Body Mass Index; HOMA-IR: Homeostasis Model Assessment of Insulin Resistance, Adopting the Formula: Fasting Insulin (mU/mL) x Fasting Glucose (nmol/L)/22.5; AST: Aspartate Aminotransferase; ALT: Alanine Aminotransferase; GGT: Gamma-Glutamyl Transferase; ULN: Upper Limit of Normal; PPA: Periportal Activity; OR: Odds Ratio; 95\% Cl: 95\% Confidence Interval. The AST, ALT and GGT cut-off values were obtained from the ROC curve. 
The levels of ALT in these patients were associated with periportal activity upon liver histology in univariate (score 13.984; $\mathrm{p}<0.001)$ and multivariate analysis [1.364 (1.030-1.805); $\mathrm{p}=0.030$ ), confirming the relationship of this enzyme with inflammatory activity in the disease. On the other hand, liver steatosis was associated with age $>50$ years (OR 1.029, $p=0.008$ ), HCV non-genotype 1 (OR 1.901, $\mathrm{p}=0.035$ ), and elevated ferritin levels (OR 2.092, $\mathrm{p}=0.0015$ ) (Table 5).

Table 5: Multivariate logistic regression analysis of factors associated with elevation of serum gamma-glutamyl transferase levels in the patients with chronic hepatitis $\mathrm{C}$ studied.

\begin{tabular}{|c|c|c|c|}
\hline Variable & OR & $\mathbf{9 5 \%} \mathbf{C I}$ & $\mathbf{p}$ \\
\hline $\begin{array}{c}\text { Ferritin }(\text { male }>400 \mathrm{ug} / \mathrm{L} ; \\
\text { female }>150 \mathrm{ug} / \mathrm{L})\end{array}$ & 2.639 & $1.489-4.678$ & $0.001^{*}$ \\
\hline HOMA-IR $(<\mathrm{or} \geq 2.5)$ & 3.119 & $1.703-5.713$ & $<0.001^{*}$ \\
\hline Stage $(0,1,2 \times 3,4)$ & 1.536. & $1.215-1.941$ & $<0.001^{*}$ \\
\hline PPA $(0,1 \times 2,3,4)$ & 0,886 & - & - \\
\hline Steatosis $(0 \times 1,2,3)$ & 1.194 & - & - \\
\hline
\end{tabular}

The following variables were included in univariate analysis: gender age, body mass index, alkaline phosphatase, AST, ALT, Ferritin, HOMA-IR, stage, PPA and steatosis, but only variables achieving statistical significance were submitted to multivariate analysis: Body Mass Index; HOMA-IR: Homeostasis Model Assessment of insulin resistance, adopting the formula: fasting insulin $(\mathrm{mU} / \mathrm{mL}) \times$ fasting glucose (nmoI/L)/22.5; AST: Aspartate Aminotransferase; ALT: Alanine Aminotransferase; GGT: Gamma-Glutamyl Transferase; PPA: Periportal Activity. The AST, ALT and GGT cut-off values were obtained from the ROC curve.

\section{Discussion}

Epidemiological studies have indicated renal failure, hematological diseases, liver diseases, abusive alcohol consumption, neoplasms, and inflammatory diseases as the most common causes of hyperferritinemia in clinical practice $[14,15]$. In chronic hepatitis $C$, the prevalence of hyperferritinemia is highly variable depending on the method and cut-off value used and the population selection criteria. Regarding the latter factor, comparison of ferritin values according to age and gender (Table 1) showed that in fact gender and not age was the determinant factor of serum ferritin concentration. In the present series, considering the cut-off values adopted, $48 \%$ of the patients had elevated ferritin levels. This percentage agrees with the study of Lange et al, [16] who also used gender-specific cut-offs but is much higher than that reported by other authors $[17,18]$. Part of this prevalence can be attributed to the larger number of patients with liver cirrhosis (23.5\% of patients) in our sample.

Despite the bias of a retrospectively analysis, with limitations in the clinical and laboratory assessment of patients such as the lack of genetic study for hemochromatosis, the sample of 282 patients is robust and we selected criteria that permitted homogeneous evaluation of the factors involved in the elevation of serum ferritin levels in patients chronically infected with HCV. Regression analysis identified serum ALT and GGT levels, HOMA-
IR, steatosis and liver siderosis as factors that were independently associated with hyperferritinemia.

Whereas almost half the patients had hyperferritinemia, iron deposition in the liver was detected histologically in only $20 \%$ of cases in sinusoidal cells and/or hepatocytes, as reported in other studies. Silva et al. [17], studying 96 patients with chronic hepatitis C including 27\% with elevated ferritin levels, found stainable iron upon histology in only $15.6 \%$. The authors observed a significant correlation between this finding and hepatic iron concentration. It should be noted that elevated serum iron in tissue was only observed in $5 \%$ of the cases of that study [17], in agreement with Thorbun et al, [19] who identified elevated hepatic iron concentrations in only $3 \%$ and $10 \%$ of patients with chronic hepatitis C, respectively. As tissue iron can not be responsible for all observed cases of elevated serum ferritin levels, factors other than liver siderosis seem to be associated with hyperferritinemia in chronic hepatitis C [20]. Numerous other factors have been related to the increase in serum ferritin, including insulin resistance of type 2 diabetes mellitus [21-23], metabolic syndrome, hepatic steatosis $[10,24,25]$, increased oxidative stress [3,26,27], liver fibrosis stage $[28,29]$ and inflammatory activity $[20,26]$.

In the present study, an association was observed between ALT and ferritin, as also reported by other authors [30-32]. This independent relationship was even found in the presence of periportal activity and disease stage, suggesting that ALT overlaps the histological finding. However, sub-analysis showed that necroinflammatory activity expressed as periportal activity was indeed the main factor associated with the increase in ALT levels. This association of ALT with ferritin supports the concept of this parameter of iron metabolism as an inflammatory acute-phase protein.

Another factor associated with serum ferritin levels was GGT activity. Given that multiple factors are associated with the activity of this enzyme in hepatitis C $[28,33]$, among our patients insulin resistance and disease stage were found to be independently associated with the activity of this enzyme (data not shown). The relationship between serum GGT levels and the degree of liver fibrosis has been recognized by several authors [17,34]. Elevated GGT in patients with steatosis and insulin resistance can be attributed to the presence of oxidative stress since this enzyme participates in the metabolism of conjugates of glutathione, the main antioxidant agent in the liver. This would also explain its relationship with ferritinemia, another marker of oxidative stress $[8,35,36]$.

It should also be remembered that patients with chronic hepatitis $\mathrm{C}$ are a high-risk population for developing diabetes $[37,38]$. Using data from the Third National Health and Nutrition Examination Survey (NHANES-III), Shaheen et al. [24] found hepatitis $\mathrm{C}$ to be associated with insulin resistance (measured by HOMA- IR) and elevated ferritin levels. Serum level of this iron transporter were a strong predictor of insulin resistance and 
future development of type 2 diabetes, in agreement with our findings showing that hyperferritinemia in hepatitis $\mathrm{C}$ was directly related to the HOMA-IR index in both univariate and multivariate analysis. Supporting this relationship, in another study using multivariate logistic regression analysis, insulinemia and ferritin were also independently associated with HCV [39]. Lecube et al [38], studying 634 non-cirrhotic patients with chronic hepatitis C, also found diabetes mellitus to be the main factor associated with ferritin elevation. Furthermore, the relationship between insulin resistance and ferritinemia has been described in other populations $[6,7,40]$. The installation of insulin resistance is the link between HCV infection and a higher risk of type 2 diabetes in patients without other risk factors. This insulin resistance would result from the direct action of the viral core protein and/ or release of inflammatory cytokines and may regress after viral elimination [41-44].

The prevalence of steatosis of $65 \%$ found in this series is similar to that reported in studies conducted at the same service or in a population of the same urban center $[11,17]$. The factors associated with hepatic steatosis in this study were ferritinemia, insulin resistance and non-genotype 1 , which are known to be related to this histological alteration. Several studies have found an association between elevated serum ferritin and the presence and degree of steatosis in patients with hepatitis $\mathrm{C}$ and with liver diseases of other etiologies [8,25,45-47], demonstrating a causal relationship independent of the presence of HCV. It is believed that ferritinemia is related to an increase in oxidative stress, which favors alterations in glucose metabolism and hepatic steatosis in this group of patients because of the interference with the secretion of apolipoprotein B by hepatocytes [48].

In this study, we were unable to establish a direct relationship between fibrosis and ferritin, as observed by other authors $[16,49]$, probably because three other factors associated with the degree of liver fibrosis may have masked the importance of this structural alteration in the logistic regression analysis, i.e., insulin resistance, siderosis and serum GGT activity. It should be remembered that insulin resistance is associated with the progression of liver disease in chronic HCV infection [1,44].

\section{Conclusion}

In conclusion, hyperferritinemia has a multifactorial etiology in treatment-naïve patients with chronic hepatitis $\mathrm{C}$ and is related to liver siderosis, insulin resistance and hepatic steatosis, in addition to serum GGT and ALT activity. In this respect, the hepatic enzymes probably indirectly reflect the inflammatory activity (represented by ALT levels) and, to a lesser extent, the changes in hepatic structure (represented by GGT levels). Oxidative stress may be the common factor linking these conditions.

\section{References}

1. Valenti L, Dongiovanni P, Fracanzani AL, Santorelli G, Fatta E, et al. (2003) Increased susceptibility to nonalcoholic fatty liver disease in heterozygotes for the mutation responsible for hereditary hemochromatosis. Dig Liver Dis 35(3): 172-178.

2. Furutani T, Hino K, Okuda M, Gondo T, Nishina S, et al. (2006) Hepatic iron overload induces hepatocellular carcinoma in transgenic mice expressing the hepatitis C virus polyprotein. Gastroenterology 130(7): 2087-2098.

3. Fujita N, Horiike S, Sugimoto R, Tanaka H, Iwasa M, et al. (2007) Hepatic oxidative DNA damage correlates with iron overload in chronic hepatitis C patients. Free Radic Biol Med 42(3):353-362.

4. Nichina S, Hino K, Korenaga M, Vecchio C, Pietrangelo A, et al. (2008) Hepatitis C virus-induced reactive oxygen species raise hepatic iron level in mice reducing hepcidin transcription. Gastroenterology 124(1): 226-238.

5. Stechemesse L, Eder SK, Wagner A, Patsch W, Feldman A, et al. (2016) Metabolomic profiling identifies potential pathways involved in the interaction of iron homeostasis with glucose metabolism. Mol Metab 6(1): 38-44.

6. Aguirre LG, Urrunaga-Pastor D, Mocada-Mapelli E, Guarnizo-Poma M, Lazaro-Alcantara H, et al. (2017) High serum ferritin levels are associated with insulin resistance but not with impaired glucose tolerance in a healthy people population. Diabetes Metab Syndr (Suppl 2): S983-988.

7. Lecube A, Herández C, Simó R (2009) Glucose abnormalities in nonalcoholic fatty liver disease and chronic hepatitis $\mathrm{C}$ virus infection: the role of iron overload. Diabetes Metab 25(5):403-410.

8. Licata A, Nebbia ME, Cabibbo G, Iacono GL, Barbaria F, et al. (2009) Hyperferritinemia is a risk factor for steatosis in chronic liver disease. World J Gastroenterol 15(17): 2132-2138.

9. Ladero JM, Lopez-Alonso G, Devesa MJ, Cuenca F (2009) Oscillations in serum ferritin associated with antiviral therapy in chronic hepatitis C. Rev Esp Enferm Dig 101(1): 31-40.

10. Matthews DR, Hosker JP, Rudenski AS, Naylor BA, Treacher DF, et al (1985) Homeostasis model assessment: insulin resistance and betacell function from fasting plasma glucose and insulin concentrations in man. Diabetologia 28(7): 412-419.

11. Oliveira AC, Parise ER, Catarino RM, Lanzoni V, Leite Mór MMB, et al. (2009) Insulin resistance and not steatosis is associated with modifications in oxidative stress markers in chronic hepatitis C, non-3 genotype. Free Rad Res 43(12): 1187-1194.

12. Gayotto LCC, Comitê SBP/SBH (2000) Visão histórica e consenso nacional sobre a classificação das hepatites crônicas. Projeto do Clube de Patologia Hepática da Sociedade Brasileira de Patologia aprovado pela Sociedade Brasileira de Hepatologia. GED Gastroenterol Endosc Dig 19: 137-140.

13. Searle J, Kerr FFR, Halliday JW, Powell LW (2002) Iron storage disease. In: mac Sween RNM, Burt AD, Portmann BCP, Ishac KG, Scheuer PJ, Anthony PP (Edt.), Pathology of the liver. Churchill Livingstone, New York, USA, pp. 219-241.

14. Kaltwassel JP, Lothar Thomas (1998) Clinical Laboratory Diagnostics. Frankfurt, TH-Books, pp. 278-281.

15. Kirchbaum B (2001) Profiling hemodialysis patients with high ferritin levels. Clin Nephro 1 56(2): 117-123. 
16. Lange CM, Kutalik Z, Morikawa K, Bibert S, Cerny A, et al. (2012) Serum ferritin levels are associated with a distinct phenotype of chronic hepatitis $\mathrm{C}$ poorly responding to pegylated interferon- alpha and ribavirin therapy. Hepatology 55(4): 1038-1047.

17. Silva IS, Perez RM, Oliveira PV, Cantagalo MI, Dantas E, et al. (2005) Iron overload in patients with chronic hepatitis $C$ virus infection: clinical and histological study. J Gastroenterol Hepatol 20(2):243-248.

18. Kageyama F, Kobayashi Y, Kawasaki T, Toyokuni S, Uchida K, et al. (2000) Successful interferon therapy reverses enhanced hepatic iron accumulation and lipid peroxidation in chronic hepatitis C. Am J Gastroenterol 95(4): 1041-1050.

19. Thorburn D, Curry G, Spooner R, Spence E, Oien K, et al. (2002) The role of iron and haemochromatosis gene mutations in the progression of liver disease in chronic hepatitis C. Gut 50(2):248-252.

20. Sumida Y, Kanemasa K, Fukumoto K, Yoshida N, Sakai K (2007) Correlation of hepatic steatosis with body mass index, serum ferritin level and hepatic fibrosis in Japanese patients with chronic hepatitis C. Hepatol Res 37(4): 263-269.

21. Iwasaki T, Nakajima A, Yoneda M, Yamada Y, Mukasa K, et al. (2005) Serum ferritin is associated with visceral fat area and subcutaneous fat area. Diabetes Care 28(10): 2486-2491.

22. Maeno T, Okumura A, Ishikawa T, Kato K, Sakakibara F, et al. (2003) Mechanisms of increased insulin resistance in non-cirrhotic patients with chronic hepatitis C virus infection. J Gastronterol. Hepatol 18(12) 1358-1363.

23. Elsammak M, Refai W, Elsawaf A, Abdel-Fattah I, Abd Elatti E, et al. (2005) Elevated serum tumor necrosis factor alpha and ferritin may contribute to the insulin resistance found in HCV positive Egyptian patients. Curr Med Res Opin 21(4): 527-534.

24. Shaheen M, Echeverry D, Oblad MG, Montoya MI, Teklehaimanot S, et al (2007) Hepatitis C, metabolic syndrome, and inflammatory markers results from the Third National Health and Nutrition Examination Survey [NHANES III]. Diabetes Res Clin Pract 75(3): 320-326.

25. Sebastiani G, Vario A, Ferrari A, Pistis R, Noventa F, et al. (2005) Hepatic iron, liver steatosis and viral genotypes in patients with chronic hepatitis C. J Viral Hepat 13(3): 199-205.

26. Mitsuyoshi H, Itoh Y, Sumida Y, Minami M, Yasui K, et al. (2008) Evidence of oxidative stress as a cofactor in the development of insulin resistance in patients with chronic hepatitis C. Hepatology research 38(4): 348-353.

27. Sumida Y, Nakashima T, Yoh T, Kakisaka Y, Nakajima Y, et al. (2001) Serum thioredoxin elucidates the significance of serum ferritin as a marker of oxidative stress in chronic liver diseases. Liver 21(5): 295299

28. Huang CF, Chuang WL, Yu ML (2016) Interference of diabetes on the association of - glutamyl transpeptidase to platelet ratio with liver fibrosis in chronic hepatitis C. Kaohsiung J Med Sci 32(6): 334-335.

29. Metwally MA, Zein CO, Zein NN (2004) Clinical significance of hepatic iron deposition and serum iron values in patients with chronic hepatitis C infection. Am J Gastroenterol 99(2): 286-291.

30. Lin TJ, Liao LY, Lin SY, Lin CL, Chang TA (2006) Influence of iron on the severity of hepatic fibrosis in patients with chronic hepatitis C. World Gastroenterol 12(30): 4897-4901.

31. Oguz A, Atay AE, Tas A, Seven G, Koruk M (2013) Predictive role of acute phase reactants in the response to therapy in patients with chronic hepatitis $C$ virus infection. Gut Liver 7(1): 82-88.
32. Atta M, Cabral M, Santos G, Paraná R, Atta A (2012) Inflammation biomarkers in chronic hepatitis C: association with liver histopathology, HCV genotype and cryoglobulinemia. Inflamm Res 61(10): 1101-1106.

33. Music M, Dervisevic A, Pepic E, Lepara O, Fajkic A, et al. (2015) Metabolic syndrome and serum liver enzymes level at patients with type 2 diabetes mellitus. Med Arch 69(4): 251-255.

34. Poynard T, Bedossa P, Opolon P (1997) Natural history of liver fibrosis progression in patients with chronic hepatitis C. The OBSVIRC, METAVIR, CLINIVIR, and DOSVIRC groups. Lancet 349(9055): 825832 .

35. Lee DH, Steffes MW, Jacobs DR Jr (2008) Can persistent organic pollutants explain the association between serum gamma-glutamyl transferase and type 2 diabetes? Diabetologia 51(3): 402-407.

36. Venturini D, Simão AN, Barbosa DS, Lavado EL, Narciso VE, et al. (2010) Increased oxidative stress, decreased total antioxidant capacity, and iron overload in untreated patients with chronic hepatitis C. Dig Dis Sci 55(4): 1120-1127.

37. Elsammak M, Refai W, Elsawaf A, Abdel-Fattah I, Abd Elatti E, et al. (2005) Elevated serum tumor necrosis factor alpha and ferritin may contribute to the insulin resistance found in HCV positive Egyptian patients. Curr Med Res Opin 21(4): 527-534.

38. Lecube A, Hernández C, Genescà J, Esteban JI, Jardí R, et al. (2004) Diabetes is the main factor accounting for the high ferritin levels detected in chronic hepatitis C virus infection. Diabetes Care 27(11): 2669-2675.

39. Garrido-Serrano A, Guerrero Igea FJ, Lepe Jiménez JA, Palomo Gil S, Grilo Reina A (2001) Hepatitis C virus infection, increased serum ferritin and hyperinsulinemia. Rev Esp Enferm Dig 93(10): 639-648.

40. Jehn M, Clark J, Guallar E (2004) Serum ferritin and risk of the metabolic syndrome in U.S. adults. Diabetes Care 27(10): 2422-2428.

41. Fukui M, Kitagawa Y, Nakamura N, Yoshikawa T (2002) Response to Oncül. Insulin sensitivity in patients with chronic hepatitis $\mathrm{C}$ virus infection [letter]. Diabetes Care 25(10): 1900-1901.

42. Malaguarnera M, Di Fazio I, Romeo MA, Restuccia S, Laurino A, et al. (1997) Elevation of interleukin 6 levels in patients with chronic hepatitis due to hepatitis C virus. J Gastroenterol 32(2):211-215.

43. Parise ER, Oliveira AC (2007) Insulin resistance in chronic hepatitis C. Arq Gastroenterol. 44: 178-184.

44. Su AI, Pezacki JP, Wodicka L, Brideau AD, Superkova L, et al. (2002) Genomic analysis of the host response to hepatitis. C virus infection. Proc Natl Acad Sci USA 99: 15669-15674

45. Rubbia-Brandt L, Fabris P, Paganin S, Leandro G, Male PJ, et al. (2004) Steatosis affects chronic hepatitis $C$ progression in a genotype specific way. Gut 53(3): 406-412.

46. Lonardo A, Loria P, Adinolfi LE, Carulli N, Ruggiero G (2006) Hepatitis C and steatosis: a reappraisal. J Viral Hepat 13: 73-80.

47. Sumida Y, Kanemasa K, Fukumoto K, Yoshida N, Sakai K (2007) Hepatic iron accumulation may be associated with insulin resistance in patients with chronic hepatitis C. Hepatology Research 37(11):932-940.

48. Hevi S, Chuck SL (2003) Ferritins can regulate the secretion of apolipoprotein B. J Biol Chem 278(34): 31924-31929.

49. Yoneda M, Thomas E, Sumida Y, Imajo K, Eguchi Y, et al. (2014) Clinical usage of serum ferritin to assess liver fibrosis in patients with nonalcoholic fatty liver disease: Proceed with caution. Hepatol Res 44(14): 499-502. 
